\title{
PVC Membrane perchlorate Anion Sensor for $[\mathrm{NiL}] \mathrm{SO}_{4}$
}

\author{
Sulekh Chandra ${ }^{1}$, Smriti Raizada ${ }^{2}$ And Seema Sharma ${ }^{2}$ \\ ${ }^{I}$ Department of Chemistry, Zakir Husain Delhi College (University of Delhi), New Delhi, India \\ ${ }^{2}$ Department of Chemistry, M. M. H. College (C. C. S. University, Meerut), Ghaziabad, India
}

\begin{abstract}
Spectroscopic studies of the interaction between Nickel sulphate complex of the ligand, 5,15dibromo-10,21-diethyl-9,11,20,22-tetramethyl-1,8,12,19-tetraazadicosa-9,11,20,22-tetraene, shown in [figure 1] showed a selective interaction between complex and perchlorate anion respect to the other anions tested. The sensor worked well with a Nernstian response of $1.0 \times 10^{-1}-7.0 \times 10^{-7} \mathrm{M}$, detection limit $4 \times 10^{-7} \mathrm{M}$. The electrode had relatively short response time, 6 s, and it was found to produce stable responses for more than two months. It was also used for monitoring of perchlorate ion concentration in water and urine samples.
\end{abstract}<smiles>CC(=O)C(C)C(C)=O</smiles>

Figure 1 Structure of the Ligand of the Ionophore used.

\section{Introduction}

Perchlorate is regarded as a new emerging persistent inorganic contaminant because of its specific properties, such as high water solubility, mobility and considerable stability [1]. One of the major sources of this environmental contamination is the manufacture or improper storage or disposal of ammonium perchlorate which is used as a primary component of solid propellant for rockets, missiles, fireworks [2], or explosives in various military ammunitions and air bag inflators. Perchlorate has also been found in food products [3-4], soil [5], milk [6], fertilizers, plants [7] and in human urine [8].

The perchlorate and iodide ion have a similar size, therefore can be taken up in place of it by the mammalian thyroid gland. In this way, perchlorate can be affected on the production of thyroid hormones. Moreover, other physiologic systems may be indirectly affected. It is due to the abnormalities in child development and the thyroid cancer. It poses the greatest threat in the drinking water of expectant mothers, children under 12 years and persons with malfunctioning thyroids. Perchlorate ions have also been applied as growth promoters and as thyreostatic drugs in cattle fattening. Thyroid gland tumors were spotted in rodent animals after exposure to high dose of perchlorate [9]. The toxicologic mechanisms through which perchlorate exerts its effects have been reviewed in some reports [10-12]. Therefore, determination of perchlorate ion in various samples such as ground water, propellants, explosives and urine in the presence of other anions is of special importance.

In this work, we describe [NiL] $\mathrm{SO}_{4}$ [Figure. 2] as a novel ionophore used in $\mathrm{PVC}$ polymeric perchlorate selective electrode.

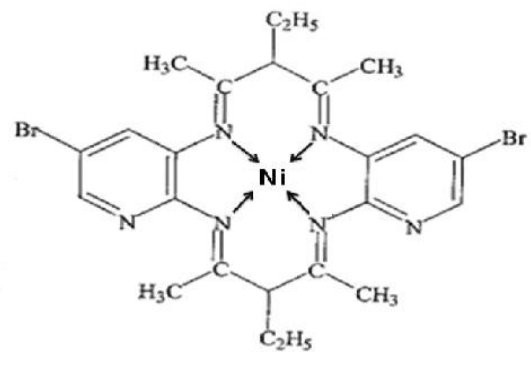

Figure 2 ionophore $[\mathrm{NiL}] \mathrm{SO}_{4}$ 


\section{Experimental}

\section{Reagents and Instruments}

High molecular weight PVC and plasticizers such as benzyl acetate (BA), nitrobenzene (NB), dibutyl phthalate (DBP), acetophenone (AP), Tri-n-butylphosphate(TBP), hexadecyltrimethylammonium chloride (HTAC), tetrahydrofuran (THF) were purchased from Fluka and used as received. Metallic salts used (all from Merck, Aldrich), were of the highest purity and used without any further purification except for vacuum drying over $\mathrm{P}_{4} \mathrm{O}_{10}$. Triply distilled water was throughly used.

Potentials were measured with digital potentiometer EQ-602 Equiptronics (accuracy, 0.001 V, India). The $\mathrm{pH}$ measurements were carried out on digital $\mathrm{pH}$ meter (LabIndia $\mathrm{pH}$ Conmeter, India). Auto ranging Conductivity meter/TDS meter TCM-15 (Toshniwal Instruments Mfg. Pvt. Ltd Ajmer).

\section{Electrode preparation.}

Different compositions of membrane ingredients, including ionophore, the plasticizers DBP, BA, AP, NB, TBP, the additive HTAC and PVC (Table 1), were thoroughly dissolved in $10 \mathrm{ml}$ THF. The resulting solution was carefully cast in to a glass dish of $2 \mathrm{~cm}$ diameter for slow evaporation at room temperature to obtain membrane of about $0.3 \mathrm{~mm}$ thickness with optimum composition and behavior. The membrane was cut and pasted to the one end of pyrex tube with the help of araldite. The tubes were then filled with an internal filling solution $\left.\left(1.0 \times 10^{-2} \mathrm{M} \mathrm{NaClO}\right)_{4}\right)$. The electrodes were finally conditioned for $24 \mathrm{~h}$ by soaking in a $1.0 \times 10^{-2} \mathrm{M}$ solution of $\mathrm{NaClO}_{4}$. When not in use, the electrode was kept immersed in the same solution. A silver/silver chloride coated wire was used as an internal reference electrode.

\section{Emf measurements}

All emf measurements were carried out with the following assembly:

$\mathrm{Hg}_{2} \mathrm{Cl}_{2}, \mathrm{KCl}$ (satd.) ||sample solution | membrane | internal solution $1.0 \times 10^{-2} \mathrm{~mol} \mathrm{~L}^{-1} \mathrm{NaClO}_{4} \mid \mathrm{Ag}-\mathrm{AgCl}$.

The detection limit was defined as the intersection of the extrapolated linear regions of the calibration graph. Selectivity coefficients for the different anions with respect to perchlorate were determined by the fixed interference method. Activities were calculated according to the Debye-Huckel procedure.

\section{Results and discussion}

The selectivity behaviour of a certain ion selective sensor is greately dependent on the ionophore used [13-26]. In preliminary experiments, investigations were conducted to determine the anionic response of the $[\mathrm{NiL}] \mathrm{SO}_{4}$ based membranes. Among all of anions studied, the electrode based on ionophore was found to be highly selective for perchlorate over a wide variety of organic and inorganic anions.[Figure. 3]

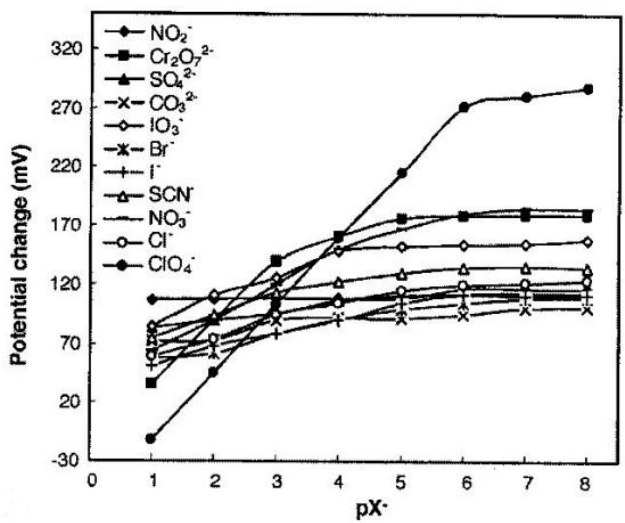

Figure 3 Potential response of various anion selective electrodes.

\section{UV-Vis. spectra}

To obtain a clue about the interaction mechanism of [NiL] $\mathrm{SO}_{4}$ with perchlorate, the UV-Vis. spectra of $1.0 \times 10^{-4} \mathrm{~mol} \mathrm{~L}^{-1}[\mathrm{NiL}] \mathrm{SO}_{4}$ in DMSO were obtained with and without the presence of $1.0 \times 10^{-4} \mathrm{~mol} \mathrm{~L}^{-1}$ perchlorate and the results are shown in [Figure 4]. A comparison between the two spectra in [Figure 4] reveals that the addition of perchlorate $\square$ to a $[\mathrm{NiL}] \mathrm{SO}_{4}$ solution in DMSO considerably increases the absorbance maxima of ionophore located at $220 \mathrm{~nm}$. The observed changes suggest the occurrence of a specific interaction between $[\mathrm{NiL}] \mathrm{SO}_{4}$ and perchlorate ion. 


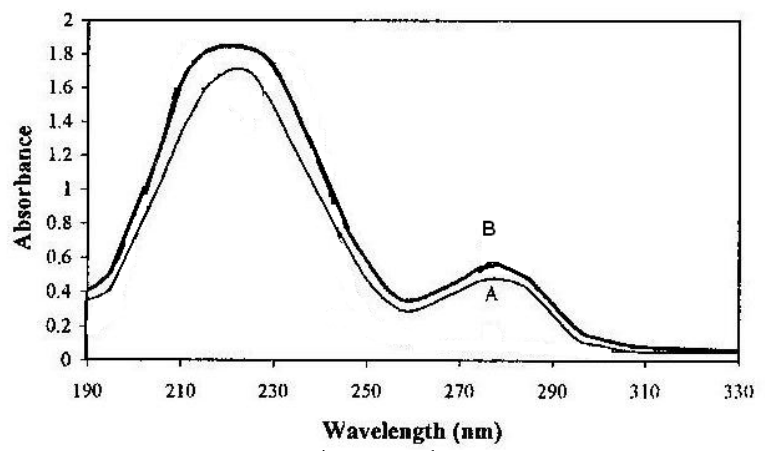

Figure 4 UV/Vis absorption spectra of (A) $1.0 \times 10^{-4} \mathrm{~mol} \mathrm{~L}^{-1}$ ionophore [NiL] $\mathrm{SO}_{4}$ in DMSO and (B) ionophore+ perchlorate.

\section{Effect of the plasticizers}

To compare the effect of the various plasticizers on response characteristics of the electrodes, the electrodes based on [NiL]SO ${ }_{4}$ prepared with TBP, AP, NB, BA and DBP were tested in $\mathrm{ClO}_{4}{ }^{-}$solutions. [Figure 5]. The results in [Figure 5] show that the EMF responses to $\mathrm{ClO}_{4}^{-}$were strongly influenced by changes in the plasticizer. Membrane electrodes prepared with BA showed the widest linear range, Nernstian response and a very low detection limit. On the other hand, the use of AP and DBP as plasticizers led only to poor responses. The reason for these phenomena might be that the polarity of the plasticizer affects the response characteristics of the electrodes. The relatively non-polar AP and DBP result in a worse solvation of ionophore than BA.

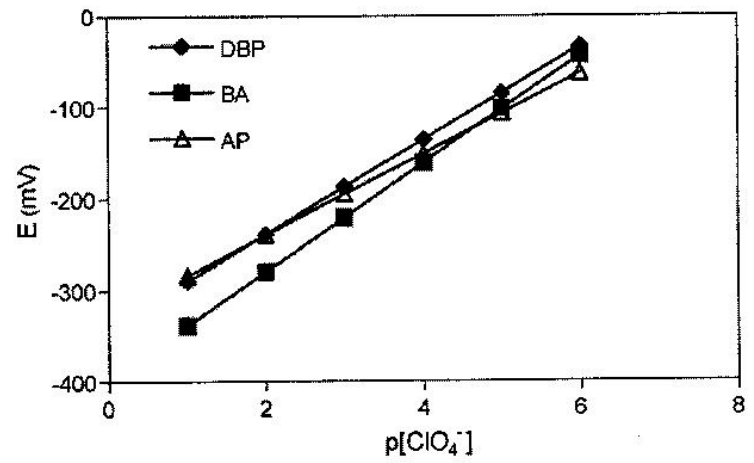

Figure 5 Effect of the plasticizers on the potential response of the perchlorate sensor.

\section{Effect of membrane composition}

It is well known that the sensitivity and selectivity obtained for a given ionophore depend significantly on the membrane composition. Thus, the influences of the amount of the ionophore, the nature and amount of the plasticizer, and the nature of additive on the optimal response of the membrane sensors were investigated, while keeping the PVC plasticizer ratio at about 1:2. The results are summarized in Table 1 and Figure 5.

Table 1 Membrane composition and response characteristics of the electrodes.

\begin{tabular}{|c|c|c|c|c|c|}
\hline \multirow{2}{*}{$\begin{array}{l}\text { Electrode } \\
\text { Number PVC }\end{array}$} & \multicolumn{5}{|c|}{ Composition of the membrane(wt.\%) } \\
\hline & Plasticizer & & Ionophore & HTAC & Slope(mV/decade) \\
\hline 1 & 33 & $65, \mathrm{BA}$ & 2 & - & $46.2 \pm 0.2$ \\
\hline 2 & 33 & 65, TBP & 2 & & $25.8 \pm 0.4$ \\
\hline 3 & 33 & $65, \mathrm{DBP}$ & 2 & - & $30.1 \pm 0.2$ \\
\hline 4 & 33 & $65, \mathrm{NB}$ & 2 & - & $17.6 \pm 0.5$ \\
\hline 5 & 33 & $65, \mathrm{AP}$ & 2 & - & $24.8 \pm 0.6$ \\
\hline 6 & 33 & $64, \mathrm{BA}$ & 2 & 1 & $50.2 \pm 0.7$ \\
\hline 7 & 33 & $63, \mathrm{BA}$ & 3 & 1 & $52.8 \pm 0.4$ \\
\hline 8 & 33 & $62, \mathrm{BA}$ & 3 & 2 & $54.6 \pm 0.6$ \\
\hline 9 & 33 & $61, \mathrm{BA}$ & 3 & 3 & $59.1 \pm 0.2$ \\
\hline 10 & 33 & $61, \mathrm{BA}$ & 4 & 2 & $55.8 \pm 0.4$ \\
\hline
\end{tabular}


The data given in Table 1 revealed that in the presence of a proper additive such as HTAC, the sensitivity of the PVC membranes would improve considerably (membranes 6-10). In the absence of ionic additives in the membrane, the response of the membrane is based on very weak interaction of nickel atoms (as a relatively soft atom) and perchlorate ions. Thus, the response and consequently the slope will be very low. In the presence of cationic additives HTAC, there are two interactions. Weak interaction of the ionophore with perchlorate and relatively strong response of HTAC to perchlorate as an ion exchanger, and therefore the slope of the sensor will be closed to the Nernstian values.

However, the membrane no. 9 with PVC:BA:I:HTAC percent ratio of 33:62:5:3 revealed Nernstian potential response over a wide concentration range.

\section{Effect of concentration of the internal solution}

The influence of the concentration of the internal solution on the potential response of the $\mathrm{ClO}_{4}{ }^{-}$ionselective electrodes were studied and the results showed the concentration of the internal solution does not cause any significant difference in the potential response of the electrodes, except for an expected change in the intercept of the resulting Nernstian plots. Figure 6.

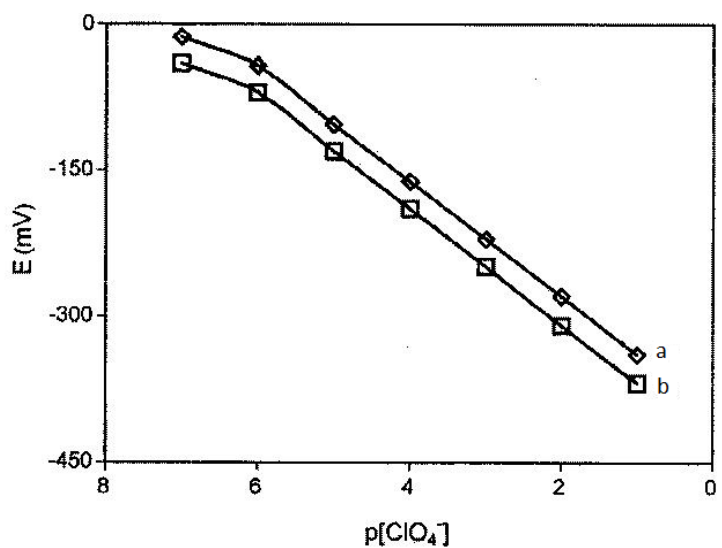

Figure 6Potential response of the perchlorate ion-selective electrodes based on $\left[\mathrm{NiL}^{-\mathrm{SO}_{4}}\right.$ (a) $1.0 \mathrm{X} 10^{-2} \mathrm{M}$ and (b) $1.0 \times \mathrm{X0}^{-4} \mathrm{M} \mathrm{ClO}_{4}^{-}$.

\section{Optimum equilibration time}

The measuring range of ion selective electrodes refers to the linear part of the calibration graph. According to IUPAC definition, the measuring range of an ion selective electrode is defined as the activity range between the upper and lower detection limits [27-37].The optimum equilibration time for the membrane electrodes in the presence of $1.0 \times 10^{-2} \mathrm{M} \mathrm{NaClO}_{4}$ was $8 \mathrm{~h}$, after which it would generate stable potentials in contact with the perchlorate solution. The electrode based on $[\mathrm{NiL}] \mathrm{SO}_{4}$ exhibited linear response to the concentration of $\mathrm{ClO}_{4}{ }^{-}$ions in the range of $1.0 \times 10^{-1}-7.0 \times 10^{-7} \mathrm{M}$ [Figure 6], respectively. The respective slope of calibration graph was $59.1 \pm 0.2 \mathrm{mV}$ per decade. The limit of detection, as determined from the intersection of the two extrapolated segments of the calibration graphs, was $4 \times 10^{-7} \mathrm{M}$.

\section{Dynamic response time}

Dynamic response time is an important factor for perchlorate selective electrodes.In this study, the practical response time was recorded by changing solution with different $\mathrm{ClO}_{4}{ }^{-}$concentrations from $1.0 \mathrm{X} 10^{-6}$ to1.0 X $10^{-1} \mathrm{M}$. The actual potential versus time trace for the electrode based on ionophore is shown in [Figure 7]. As can be seen, the electrode reaches the equilibrium response in a very short time of about $6 \mathrm{~s}$. To evaluate the reversibility of the electrode, a similar procedure with opposite direction was adopted. The measurements were performed in the sequence of high to low sample concentrations and the results shown in [Figure 8]. [Figure 8] shows that the potentiometric response of the sensor was reversible, although the time needed to reach equilibrium values were longer than that of low-to-high sample concentrations, it is well documented that, in the case of high-to-low concentrations, the time needed to attain a stable potential is some 100 times larger than that required for the case of low to high concentrations (for a 10 times change in the ion concentration). 


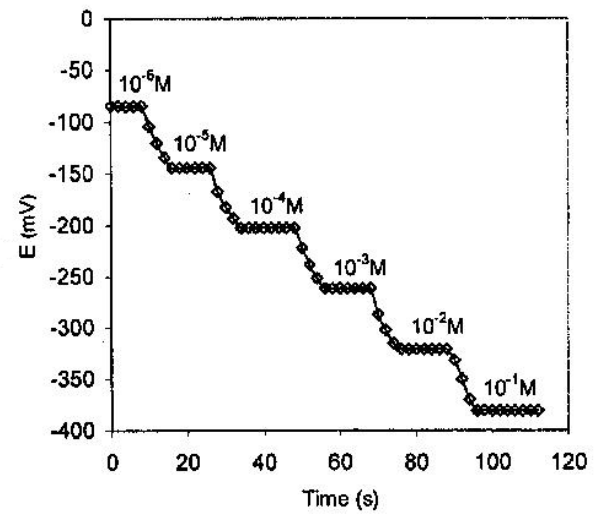

Figure 7Dynamic response time of membrane electrode (I) for step changes in concentration of $\mathrm{ClO}_{4}^{-}(\mathrm{low}$ to high).

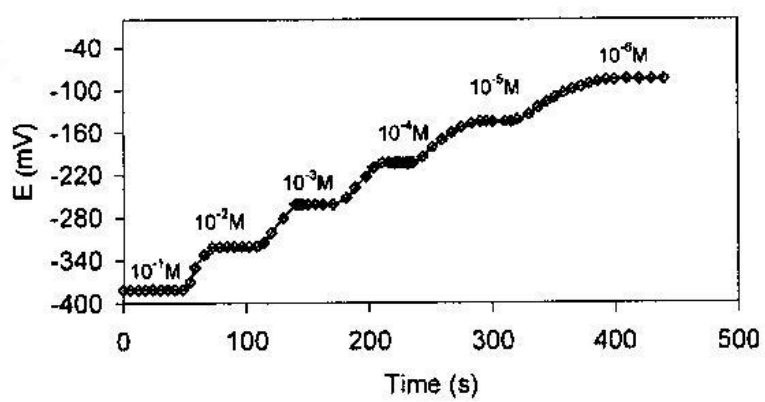

Figure 8Dynamic response time of membrane electrode (I) for step changes in concentration of $\mathrm{ClO}_{4}{ }^{-}$ (high to low).

\section{Lifetime}

The lifetime of an ion-selective electrode is usually defined as the time interval between the conditioning of the membrane and the moment when at least one of its response characteristics changes. It was observed that there was no significant change in the slope of the curve on successive days. The electrodewas tested over a period of 2 months to investigate its stability. During this period, the electrode was in a perchlorate solution $\left(1.0 \times 10^{-3} \mathrm{M}\right)$ and used everyday. The perchlorate-selective electrodeworked over a period of at least 2 months and no appreciable change in the calibration characteristics or response time was observed. During this time, the detection limit and slope of the electrodes remained almost constant. After 2 months, very slight gradual decrease in slopes was observed. It should be noted that, during these 2 months, the electrode was almost in daily use, and then it was washed with water, kept in solution if dried, and kept aside for testing in the next days.

Life time of optimized $\mathrm{ClO}_{4}^{-}$ISE

Table 2

\begin{tabular}{lcc}
\hline Linear range $(\mathrm{M})$ & Slope $\left(\mathrm{mV}\right.$ decade $\left.^{-1}\right)$ & Time $($ day $)$ \\
\hline $1.0 \times 10^{-1}-7.0 \times 10^{-7}$ & $59.1 \pm 0.2$ & 1 \\
$1.0 \times 10^{-1}-7.0 \times 10^{-7}$ & $59.1 \pm 0.2$ & 5 \\
$1.0 \times 10^{-1}-7.0 \times 10^{-7}$ & $59.1 \pm 0.2$ & 10 \\
$1.0 \times 10^{-1}-7.0 \times 10^{-7}$ & $59.1 \pm 0.2$ & 15 \\
$1.0 \times 10^{-1}-7.0 \times 10^{-7}$ & $59.1 \pm 0.2$ & 20 \\
$1.0 \times 10^{-1}-7.0 \times 10^{-7}$ & $59.1 \pm 0.2$ & 35 \\
$1.0 \times 10^{-1}-7.0 \times 10^{-7}$ & $58.5 \pm 0.5$ & 50 \\
$1.0 \times 10^{-2}-7.0 \times 10^{-7}$ & $58.5 \pm 0.5$ & 60 \\
$5.0 \times 10^{-2}-7.0 \times 10^{-7}$ & $58.0 \pm 0.5$ & 75 \\
$5.0 \times 10^{-2}-1.0 \times 10^{-6}$ & $57.5 \pm 0.5$ & 80 \\
\hline
\end{tabular}




\section{Influence of $\mathrm{pH}$}

The influence of $\mathrm{pH}$ of the test solution on the response of the membrane electrodes based on the ionophore was investigated for $1.0 \times 10^{-4}, 1.0 \times 10^{-3}$ and $1.0 \times 10^{-2} \mathrm{~mol} \mathrm{~L}{ }^{-1}$ perchlorate solutions. As can be seen from the results shown in Figure 9, the potential response of the electrode based on the carrier is independent of $\mathrm{pH}$ over the range 3.0-12.0, indicating that hydroxide ions are not considerably coordinated to the Nickel center in the complexes. Drastic potential changes were observed at higher and lower $\mathrm{pH}$ values. This is most probably due to the simultaneous response of the electrode to $4 \mathrm{ClO}^{-}$and $\mathrm{OH}^{-}$, at $\mathrm{pH}>12$, and the simultaneous response to perchlorate and nitrate ions at $\mathrm{pH}<3.5$.

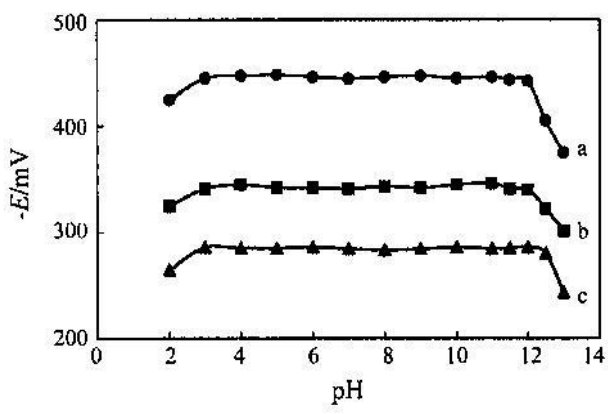

Figure 9Effect of $\mathrm{pH}$ on response of perchlorate selective electrode.

(a) $1.0 \times 10^{-4} \mathrm{~mol} \mathrm{~L}^{-1}$, (b) $1.0 \times 10^{-3} \mathrm{~mol} \mathrm{~L}^{-1}$ and (c) $1.0 \times 10{ }^{-2} \mathrm{~mol} \mathrm{~L}^{-1}$

Table 3

Response characteristics of the perchlorate-selective electrode

Slope (mVdecade ${ }^{-1}$ )
Linear range $(M)$
Detection limit $(M)$
Response time (s)
Working pH range
Life time (months)

$59.1 \pm 0.2$ mVdecade $^{-1}$

$1.0 \times 10^{-1}-7.0 \times 10^{-7} \mathrm{M}$

$4 \times 10^{-7} \mathrm{M}$

$1.0 \times 10^{-6}-7.0 \times 10^{-1} \mathrm{M} \leq 6$

3.0-12.0

Life time (months)

$>2$

\section{Effect of non-aqueous media on the electrode response.}

The performance of the proposed sensors was investigated in partially non-aqueous media using methanol, ethanol and acetone mixtures with water. The calibration plot of the electrode was obtained in the different mixture (v/v) of methanol-water, ethanol-water and acetone-water. From the data obtained Table 4, it was concluded that the membrane electrodes worked satisfactorily in mixtures upto 30\% (v/v) non-aqueous content. In these mixtures the working concentration range and slope did not change reasonably, only a little decrease was observed.

Table 4 Effect of partially non-aqueous media on the response of $\mathrm{ClO}_{4}{ }^{-}$selective polymeric membrane electrode.

\begin{tabular}{|c|c|c|}
\hline $\begin{array}{l}\text { Non-aqueous } \\
\text { Content }(\% \mathrm{v} / \mathrm{v})\end{array}$ & $\begin{array}{c}\text { Slope } \\
(\mathrm{mV} / \text { decade })\end{array}$ & Linear range $\left(\mathrm{mol} \mathrm{L}^{-1}\right)$ \\
\hline 0 & 59.3 & $3.0 \times 10^{-6}-2.5 \times 10^{-1}$ \\
\hline Methanol & & \\
\hline 10 & 59.1 & $5.0 \times 10^{-6}-2.5 \times 10^{-1}$ \\
\hline 20 & 59.0 & $5.0 \times 10^{-6}-2.5 \times 10^{-1}$ \\
\hline 30 & 58.3 & $7.5 \times 10^{-6}-1.8 \times 10^{-1}$ \\
\hline Ethanol & & \\
\hline 10 & 58.9 & $7.5 \times 10^{-6}-2.5 \times 10^{-1}$ \\
\hline 20 & 58.6 & $1.2 \times 10^{-5}-2.5 \times 10^{-1}$ \\
\hline 30 & 57.8 & $2.2 \times 10^{-5}-1.5 \times 10^{-1}$ \\
\hline Acetone & & \\
\hline 10 & 58.8 & $5.1 \times 10^{-6}-2.5 \times 10^{-1}$ \\
\hline 20 & 57.9 & $1.5 \times 10^{-5}-2.0 \times 10^{-1}$ \\
\hline 30 & 57.0 & $7.2 \times 10^{-5}-7.5 \times 10^{-2}$ \\
\hline
\end{tabular}


Procedure for the determination of perchlorate in water and urine samples

Urine and water samples at different perchlorate concentrations were prepared by adding known amounts of perchlorate to blank urine and water. The $\mathrm{pH}$ of an appropriate volume of perchlorate sample was adjusted at 7.0 by addition of an appropriative amount of $\mathrm{HCl}$ or $\mathrm{KOH}$ and the solution was diluted to $50 \mathrm{~mL}$ with distilled water. The perchlorate-selective and reference electrodes were immersed and the perchlorate concentration was determined by direct potentiometry using the standard addition technique. A blank value for the corresponding blank urine or water sample was also obtained to correct the above results.

\section{Analytical applications}

The proposed perchlorate sensors were used for the determination of perchlorate ions in river water (Imam Reza River, Behbahan, Iran), drinking water, sludgy water and human urine samples. The analyses were performed by direct potentiometry of $10.0 \mathrm{~mL}$ of water samples, which were diluted with distilled water in a $25.0 \mathrm{~mL}$ volumetric flask. The proposed perchlorate sensors measured the potential of these solutions. With the use of the calibration curve of the sensor obtained by the measurements of a series of standard solutions of perchlorate ions, the concentration of perchlorate ions in samples was determined. The results showed the perchlorate content in wastewater obtained from triplicate measurements with the sensors $\left(224.5 \pm 5.2 \mu \mathrm{g} \mathrm{mL}^{-1}\right)$. The sensors were also applied to determination of perchlorate in human urine samples by using the spiking method. Certain amounts of perchlorate ions were added to the $5 \mathrm{~mL}$ of human urine samples and finally the solutions were diluted with distilled water in $50 \mathrm{~mL}$-volume flasks. Then, the perchlorate concentrations of the sample solutions were determined by direct potentiometry. The results are given in Table 5. As seen, good recoveries were obtained in all samples.

Table 5 Determination of perchlorate in water samples and human urine samples

\begin{tabular}{|c|c|c|c|}
\hline $\begin{array}{l}\text { Sample Perchlor: } \\
/\left(\mu \mathrm{g} \mathrm{mL}^{-1}\right)\end{array}$ & & $\begin{array}{l}\text { Perchlorate found } \\
/\left(\mu \mathrm{gmL}^{-1}\right)\end{array}$ & Recovery/\% \\
\hline Sludgy water & $\begin{array}{l}0 \\
25 \\
50\end{array}$ & $\begin{array}{l}1.5 \\
20.5 \\
70.5\end{array}$ & $\begin{array}{l}- \\
101.4 \\
101.3\end{array}$ \\
\hline River water & $\begin{array}{l}0 \\
25 \\
50\end{array}$ & $\begin{array}{l}1.1 \\
20.1 \\
60.4\end{array}$ & $\begin{array}{l}- \\
104.0 \\
105.6\end{array}$ \\
\hline Drinking water & $\begin{array}{l}0 \\
5 \\
20\end{array}$ & $\begin{array}{l}0.7 \\
5.3 \\
21.5\end{array}$ & $\begin{array}{l}- \\
103.6 \\
102.4\end{array}$ \\
\hline (1) urine human & $\begin{array}{l}20 \\
25 \\
50\end{array}$ & $\begin{array}{l}1.4 \\
26.6 \\
51.7\end{array}$ & $\begin{array}{l}- \\
102.4 \\
101.6\end{array}$ \\
\hline (2) urine cattle & $\begin{array}{l}0 \\
25 \\
50\end{array}$ & $\begin{array}{l}1.4 \\
24.90 \\
48.90\end{array}$ & $\begin{array}{l}- \\
99.7 \\
98.7\end{array}$ \\
\hline
\end{tabular}

\section{References}

[1]. J. E. Canas, Q.Q. Cheng, K. Tian, T.A. Anderson, J. Chromatogr., A 20 (2006) 102-110.

[2]. M. L. Magnuson, E.T. Urbansky, C.A. Kelty, Anal. Chem., 72 (2000) 25-29.

[3]. A.J. Krynitsky, R.A. Niemann, D.A. Nortrup, Anal. Chem., 76 (2004) 5518-5522.

[4]. C. A. Sanchez, K.S. Crump, R.I. Krieger,N.R. Khandaker, J.P. Gibbs, Environ. Sci. Technol., 39 (2005) $9391-9397$.

[5]. P. Winkler, M. Minteer, J. Willey, Anal. Chem., 76 (2004) 469-473.

[6]. A. B. Kirk, E.E. Smith, K. Tian, T.A. Anderson, P.K. Dasgupta, Environ. Sci. Technol., 37 (2003) $4979-4985$.

[7]. J. J. Ellington, N.L. Wolfe, A.W. Garrison, J.J. Evans, J.K. Avants, Q. Teng, Environ. Sci. Technol., 35 (2001) $3213-3218$.

[8]. L. Valentin-Blasini, J.P. Mauldin, D. Maple, B.C. Blount, Anal. Chem., 77 (2005) 2475-2481,

[9]. D. Ting, R.A. Howd, A.M. Fan, G.V. Alexeeff, Environ Health Perspect., 114 (6) (2006) 881-886.

[10]. J.Wolff, Pharmacol. Rev., 50 (1998) 89-106.

[11]. J. J. J. Clark, Toxicology of perchlorate, in: E.T. Urbansky (Ed.), Kluwer Academic/Plenum, New York, NY, 2000 , Chapter 3.

[12]. Z. Li, L.F. Xiao, D. Byrd, G.M.Deyhle, D.E. Sesser,M.R. Skeels, S.H. Lamm, J. Occup. Environ. Med., 42 (2000) $200-205$.

[13]. J. I. Kroschwiz, M. Howe-Grant, R.E. Kirk, D.F. Othmer, Encyclopedia of Chemical Technology, vol. 18, fourth ed., Wiley, New York, pp. 167-186, (1996)

[14]. A. Soleymanpour, E. H. Asl, S. M. Nabavizadeh, Sens. Actuators B, 120 (2007) 447-454.

[15]. M. J. Segui, J. Lizondo-Sabater, R. Martinez-Manez, F. Sancenon, J. Soto, E. Garcia-Breijo, L. Gil, Sensors, 6 (2006) $480-49$. 
[16]. L. T. Di Benedetto, T. Dimitrakopoulos, J. R. Farrell, P. J. Iles, Talanta, 44 (1997) 349-356.

[17]. A. Errachid, C. Perez-Jimenez, J. Casabo, E L. scriche, J. A. Munoz, A. Bratov, J. Bausells, Sens. Actuators B, 43 (1997) 206-210,

[18]. R. Perez-Olmos, A. Rios, M. P. Martin, R. A. S. Lapa, J. Lima, Analyst, 124 (1999) 97-100.

[19]. M. R. Ganjali, Z. Memari, F. Faridbod, R. Dinarvand and P. Norouzi, Electroanalysis, 20 (2008) 2663.

[20]. M. R. Ganjali, H. Ganjali, M. Hosseini, and P. Norouzi, Int. J. Electrochem. Sci., 5 (2010) 965.

[21]. A. K. Jain, V. K. Gupta, L. P. Singh, P. Srivastava and J. R. Raisoni, Talanta 65 (2005) 716

[22]. V. K. Gupta, R. Jain, M.K. Pal, Int. J. Electrochem. Sci., 5 (2010) 1164.

[23]. F. Faridbod, M. R. Ganjali, B. Larijani, E. Nasli-Esfahani, S. Riahi, and P. Norouzi, Int. J. Electrochem. Sci., 5 (2010) 653.

[24]. M. R. Ganjali, A. Rouhollahi, A. R. Mardan, M. Hamzeloo, A. Moghimi, and M. Shamsipur, Michrochim. J., 60 (1998) 122.

[25]. M. R. Ganjali, T. Poursaberi, M. Hosseini, M. Salavati-Niasari, M. Yousefi, and M. Shamsipur, Anal. Sci., 18 (2002) 289.

[26]. M. R. Ganjali, M. Emami, M. Rezapour, M. Shamsipur, B. Maddah, M. Salavati-Niasari, M. Hosseini, Z. Talebpoui, Anal. Chim. Acta, 495 (2003) 51

[27]. M. R. Ganjali, A. Daftari, P. Norouzi, M. Salavati-Niasari, Anal. Lett., 36 (2003) 1511.

[28]. M. R. Ganjali, J. Ravanshad, M. Hosseini, M. Salavati-Niasari, M. R. Pourjavid, M. R. Baezzat, Electroanalysis, 16 (2004) 1771

[29]. M. R. Ganjali, S. Rasoolipour, M. Rezapour, P. Norouzi, A. Tajarodi, Y. Hanifehpour, Electroanalysis, 17 (2005) 1534.

[30]. M. R. Ganjali, T. Poursaberi, F. Basiripour, M. Salavati-Niasari, M. Yousefi, and M. Shamsipur, Fresenius J. Anal. Chem., 370 (2001) 1091

[31]. M. R. Ganjali, R. Kiani-Anbouhi, M. Shamsipur, T. Poursaberi, M. Salavati-Niasari, Z. Talebpour, M. Emami, Electroanalysis 16 (2004) 1002.

[32]. H. Behmadi, H. A. Zamani, M. R. Ganjali, P. Norouzi, Electrochim. Acta, 53 (2007) 1870

[33]. M. R. Ganjali, F. Aboufazeli, S. Riahi, R. Dinarvand, P. Norouzi, M. H. Ghasemi, R. Kiani-Anbuhi and S. Meftah, Int. J. Electrochem. Sci, 4 (2009) 1138

[34]. M. R. Ganjali, R. Nemati, F. Faridbod, P. Norouzi, F. Darviche, Int. J. Electrochem. Sci, 3 (2008) 1288.

[35]. Farnoush Faridbod1, Mohammad Reza Ganjali1, Morteza Hosseini, Parviz Norouzi Int. J. Electrochem. Sci., 7 (2012) 1927 - 1936.

[36]. M. R. Ganjali, S. Aghabalazadeh, M. Khoobi, A. Ramazani, A. Foroumadi, A. Shafiee and P. Norouzi, Int. J. Electrochem. Sci., 6 (2011) 52 .

[37]. M. R. Ganjali, V. K. Gupta, M. Hosseini, Z. Rafiei-Sarmazdeh, F. Faridbod, H. Goldooz, A. R. Badiei, P. Norouzi, Talanta 88 (2012) 684 . 